\section{X-RAY CRYSTALLOGRAPHY}

$T$ HE 1947 Conference of the X-ray Analysis Group of the Institute of Physics was held in the Royal Institution, London, on April 22 and 23. The first day was devoted to papers and discussion on the training of X-ray crystallographers for science and industry, and the second to descriptions of now techniques and results of X-ray analysis. The annual meeting of the Group was also held on the first day, and an evening lecture was given by Mr. H. P. Rooksby on "The Technique of X-ray Powder Photography" (see p. 7 of this issue).

It is impossible to give more in these notes than a very brief summary of the major contributions to the Conference. A fuller report will be published in the Journal of Scientific Instruments.

\section{$X$-Ray Crystallographers in Industry}

It became clear in the course of the two papers on this subject, and the discussion that followed, that there was general agreement on several interesting points. First, the demand for trained men still exceeds the supply, largely owing to a bottleneck in training; one way out of this difficulty, of which use has been made, is to send men already in industrial laboratories for short courses of training. This has the advantage that the workers are already acquainted with problems they will have to tackle, but the disadvantage that they cannot be spared for a length of time really adequate for training. Secondly, it was emphasized that a good X-ray analyst must have as broad a knowledge as possible of other sciences and techniques, in order to be able properly to assess the applications and limitations of his own technique.

Mr. D. A. Oliver suggested that a series of specialized monographs covering the whole theoretical and practical field would be useful to industrial X-ray crystallographers. He was of the opinion that, owing to general understaffing, industrial laboratories cannot usually offer much in the way of training apart from that in routine work, and that the present solution is that industry must assist in the training of research personnel by direct or indirect support of research in university departments.

Dr. L. Mullins gave details of a short course in X-ray crystallography given at Messrs. Kodak, Ltd., for industrial research personnel. Practical work includes the tackling of problems likely to arise in industry.

In the discussion, Sir Lawrence Bragg suggested that an appointments board in association with the $\mathrm{X}$-ray Analysis Group might assist in the recruiting of X-ray crystallographers for industry. Mr. H. P. Rooksby was of the opinion that an industrial worker should be able to tackle fundamental problems, for which, however, a short course is not sufficient preparation. He also believed that those undergoing academic training would benefit by a period of apprenticeship in industry. Dr. W. A. Wooster agreed that work of a fundamental nature should be carried out in industry and suggested that research could usefully be divided into three types : (1) fundamental ; (2) semi-fundamental ; (3) technical. Dr. G. A. Jeffrey suggested that research organisations, when taking on university-trained men in order to start up an X-ray crystallography department, should take men from two or more university departments in order to ensure wide application of the technique.

\section{Training of X-Ray Crystallographers in Polytechnics and Universities}

The training of post-graduate chemistry students was discussed by Prof. E. G. Cox. This starts, in most universities, at a very elementary level, which is offset by a knowledge of the importance of the results of X-ray analysis to chemical problems. It is important to build on this by giving a man a research topic from the outset, which will encourage him both to acquire the necessary $\mathrm{X}$-ray technique and also to widen his chemical horizons. Some formal instruction is considered necessary, covering crystal optics as well as X-ray analysis. Instruction in the latter is mainly concerned with structure analysis from single crystals, and here it is particularly important to find a suitable compromise between spending a great deal of time on learning to make and use equipment and do calculations, and becoming merely a machine-operator. To avoid the danger of becoming narrow-minded specialists, colloquia, visits to other workers, etc., are all important, but most important of all is the maintenance of the proper atmosphere in the laboratory.

The next speaker was Dr. H. M. Powell, who described the teaching in crystallography offered to students in chemistry at Oxford. It is realized that courses of two different types have to be provided: (a) for chemistry students generally, who need an outline knowledge of X-ray methods and their possibilities; and $(b)$ for those intending to specialize in this work. Details of courses intended to meet this need were given, and stress was laid on the Oxford system of a graduate's fourth year of study, when a one-year research problem is tackled, sometimes leading on to further work.

Mr. F. Y. Poynton described how, in spite of all the difficulties of evening-class work, successful courses on the technical applications of $\mathrm{X}$-ray diffraction had been run during the last few years, fitting into the general teaching of the Department of Applied Physics of the Northampton Polytechnic. The support of neighbouring industrial organisations had encouraged them to start recently a more detailed course for technicians beginning to use X-ray methods.

Dr. W. H. Taylor gave an account of the arrangements for teaching X-ray crystallography in Cambridge. $\mathrm{H}_{\Theta}$ described the arrangements for Parts I and $\mathbf{2}$ of the Natural Sciences Tripos, and, leaving the Part 1 teaching to be described later by Dr. W. A. Wooster, went on to explain in detail the teaching for Part 2 students in chemistry, metallurgy and physics. Recognizing the two divisions of students mentioned by Dr. Powell, he showed how the content of each course is adapted to the needs and interests of each class of student and gave details of the practical work offered. He went on to describe the postgraduate work, explaining the advantages to the general outlook of students of the wide range of research, extra-mural, and administrative problems undertaken in the Cavendish Laboratory.

Dr. W. A. Wooster gave an account of the teaching of X-ray crystallography provided in the mineralogy course for Part 1 of the Natural Sciences Tripos at Cambridge. Emphasis was laid on the carefully prepared demonstrations and practical work and on the thoroughness of the teaching of the elementary ground-work, coupled with the Cambridge system of 'supervision' or private tuition. Dr. Wooster said that his Department would be pleased to try to 
help other people setting up similar courses by supplying photographs, etc., for demonstrations. $\mathrm{He}$ concluded by describing the content of an advanced course which he would like to see established.

Dr. R. C. Evans described the Cambridge Summer Schools in X-ray analysis which had been run for a fortnight each summer for the last four years. $\mathrm{He}$ gave details of the content of the course, explaining the importance attached to fundamental principles and the practical work undertaken by the students. In the subsequent discussion, Miss O. Weisz asked whether the material of the Cambridge Summer School could be published. Dr. Evans said that only photographs, etc., were yet available, and Dr. Lipson said that he hoped soon, in conjunction with Dr. Wooster and Dr. Henry, to publish a book based on the Summer Schools.

Further discussion brought out the advantages of both advanced and 'refresher' courses, though some speakers doubted whether research workers could spare the time required for these.

Dr. A. Taylor directed attention to the difficulties under which many technical colleges are operating, but Mr. N. Tunstall explained that the Ministry of Education is well aware of the position and is making considerable progress towards its improvement.

\section{New Methods and Results of X-Ray Analysis}

Investigations of the structure of the related minerals kaolinite, halloysite and fire-clays were described by Dr. G. W. Brindley. The study of kaolinite using high-resolution powder cameras showed that the unit cell is triclinic, not monoclinic as had been previously reported. The cell contains one unit of the silicate layer structure, and the way in which the layers are packed can be decided unambiguously. The powder patterns of halloysite and meta-halloysite show bands as well as sharp lines, which indicate almost complete disorder as regards the orientation of the layers. Heat-treated halloysite loses water and the layers collapse to form metahalloysite; in the latter the layer spacing is still greater than in kaolinite, indicating that some water may still be trapped between layers. The state of crystallization of the kaolin mineral in fire-clays is intermediate between that of kaolinite and halloysite.

Mr. C. W. Bunn discussed investigations of the structurally similar $(6,6)$ and $(6,10)$ nylons or polyamides. Squeezing the fibres causes the orientations of the crystals to simulate twinning, and from these specimens it is possible to determine the triclinic unit cell, and work out the atomic positions by trial and error. It has been found that the chain molecules, which have a planar zigzag configuration, are linked by hydrogen bonds to form sheets. The sheets can pack together in two ways to form either $\alpha$-crystals which have a one-molecule triclinic cell, or $\beta$-crystals which have a two-molecule triclinic cell. However, streaks which appear on most fibre photographs indicate a certain degree of random changeover from $\alpha$ - to $\beta$-type of packing.

Dr. W. Cochran, in his paper on sucrose, pointed out that it is one of the few comparatively simple organic compounds for which the accepted stereochemical formula has never been confirmed by chemical synthesis. For this reason X-ray analysis of its structure has been attempted, but so far with no success. However, the structures of isomorphous addition compounds with sodium bromide and chloride have been completely solved by two. dimensional Fourier methods, and results indicate that the sucrose molecule can be described as 1- $\alpha$-glucopyranose-2- $\beta$-fructofuranose. The accuracy of the analysis was judged by the agreement between observed and calculated electron density distributions.

Mrs. Hodgkin gave a general account of the investigation of the structure of penicillin, and paid tribute to all those who had assisted in this work. Before X-ray work started, the chemists had proposed several possible formulæ, including (1) 'oxazolone', (2) ' $\beta$-lactam', (3) 'tricyclic'. X-ray analysis began on the sodium benzyl salt, but no progress was made with this. It was, however, possible to find the atomic positions of the alkali atoms and also the sulphur atom in the potassium and rubidium salts. Meanwhile, Mr. Bunn tried the 'fly's-eye' technique on an 'oxazolone' structure, at that time favoured by chemists, for the sodium salt, and succeeded in getting $a b$ electron-density projection which was partially correct. The $b$ projections for all three salts were re-examined and a related set of peaks found in all of them which was assumed to represent the molecule. After that the work was comparatively straightforward, and a three-dimensional synthesis proved the molecule to have the ' $\beta$-lactam' structure. Mr. C. W. Bunn described how he had used the 'fly's-eye' technique in conjunction with BraggLipson structure factor graphs, and also a new method arising out of the latter for refining atomic positions.

In the course of the discussion which followed, Dr. H. Lipson said that he believed that comparison of observed and calculated intensities is the only satisfactory method of checking the accuracy of a structure, and Prof. E. G. Cox thought that the factor

$$
\frac{\Sigma\left(F_{\text {obs }}-F_{\text {cllc }}\right)}{\Sigma F_{\text {obs }}}
$$

provides the most satisfactory check now available; although, as Mrs. Hodgkin pointed out, it is not completely reliable.

\section{New Industrial Techniques and Results}

The afternoon session was opened by Dr. J. Bailey; who gave examples of the application of X-ray crystallographic equipment to the solution of tech nical difficulties in metallurgical production.

Dr. T. Ll. Richards illustrated some metallurgical applications of the stereographic projection, including an analysis of the mechanism of recrystallization in cold-rolled $70 / 30$ brass.

Dr. H. D. Megaw, giving the first of several papers on ferro-electric compounds, described these as having an abnormally high permittivity, analogous to the high permeability of ferromagnetic materials. Of the perovskite-type group of compounds, barium titanate alone shows a distortion of the ideal cubic structure that is not compatible with Goldschmidt's principles. Barium titanate shows a reversible second-order transition at c. $120^{\circ} \mathrm{C}$. to the ideal cubic form, and there are indications that there may be another transition at a low temperature. The transition from the cubic form is accompanied by characteristic multiple twinning.

Mr. M. J. Harwood described further work on the temperature variations of the barium titanate strueture. $\mathrm{He}$ directed attention to the co-existence of both cubic and tetragonal phases in the region $120-125^{\circ} \mathrm{C}$. Showing curves for the variation of celi dimensions of each phase with temperature, he explained the details by assuming that the lattice of 
the new phase is at first built on that of the old, and that the stresses thus set up increase until they are relieved by the formation of the new phase as a separate structure.

Mr. H. F. Kay described some optical work on crystals of barium titanate which he had prepared from a melt. $\mathrm{He}$ had observed domains which were truly single-crystal, and had followed the changes occurring at the high-temperature transition and also at and below $0^{\circ} \mathrm{C}$.

Dr. L. A. Thomas described how Wooster's method of removing the Dauphiné (or 'electrical') twinning of quartz by applied heat and stress, although in general effective, had in some cases proved unsuccessful. Instead of the twin boundaries being removed, the twinned areas may show regions of persistence which can be correlated to some extent with the darkening response to irradiation with $\mathrm{X}$-rays.

Mr. H. S. Peiser discussed the determination of the amorphous : crystalline ratio in polythenes. Working to a standardized procedure, it is possible, by microphotometric intensity measurements of the amorphous and crystalline X-ray patterns, to compare the ratios for different samples to an accuracy of \pm 3 per cent.

Dr. C. J. Brown described some of the organic structure determinations carried out in his laboratory. Anthranilic acid, sodium naphthionate, acetanilide, and the new synthetic fibre 'terylene', were among the structures described.

Dr. A. F. Wells directed attention to the increasing tendency of chemists to use the results of $\mathrm{X}$-ray crystallography in an insufficiently critical manner, and pointed out the responsibility which this places on the X-ray worker.

Dr. W. J. Wrazej gave some results on the structure of retained austenite in plain carbon steels, which indicated that it should be regarded as a facecentred tetragonally distorted structure rather than face-centred cubic.

In the discussion which followed these papers, many points in connexion with the barium titanate structure were raised, it being evident that the mechanism of transition from the tetragonal to the oubic phase is still very imperfectly understood.

\section{Annual General Meeting of the X-Ray Analysis Group}

In his report as chairman of the X-ray Analysis Group of the Institute of Physics, Sir Lawrence Bragg reviewed the previous very successful year and described the steadily widening activities of the Group. Sir Lawrence now retires from the office of chairman, and Mr. D. A. Oliver (director of research, B.S.A. Group of Companies) succeeds him. It was agreed to request the Board of the Institute of Physics to approve the creation of the office of viceshairman, and Dr. W. H. Taylor (Crystallographic Laboratory, Cavendish Laboratory, Cambridge) was elected. Mr. J. N. Kellar (Crystallographic Laboratory, Cavendish Laboratory, Cambridge) was elected honorary secretary in succession to Dr. F. A. Bannister. Dr. H. Lipson, Mr. H. P. Rooksby. and Dr. A. J. C. Wilson retired from the Committee, and Dr. R. C. Evans, Dr. T. Ll. Richards, Prof. J. M. Robertson and Prof. W. T. Astbury were elected, the last subject to the Board of the Institute agreeing to augment the membership of the Committee by one.
The business of the meeting was followed by reports, given by Dr. W. H. Taylor, Dr. R. C. Evans and Dr. F. A. Bannister, on the work of the equipment panels set up in the latter part of 1946. The Fourier Service Panel has concluded that the demand for a central calculating service is not large enough to justify setting up a special organisation, and those requiring assistance can apply direct to Dr. L. J. Comrie's organisation. New and improved BeeversLipson strips are being prepared. The X-ray Tube Panel, having made a general inquiry of users in Great Britain, has prepared a user specification for an 'ideal' demountable hot-cathode X-ray tube, but is taking no action in this matter beyond passing certain recommendations for improvement to the Raymax and Hilger sets to the appropriate firms. Specifications for moving anode and sealed-off tubes are being prepared. The Single Crystal Camera Panel is proceeding with a specification for a Weissenbergtype camera. The Powder Camera Panel is proceeding to design and prepare prototypes of a hightemperature camera, with the help of Mr. Oliver's organisation. Dr. W. H. Taylor announced that it is hoped to receive, through the Ministry of Supply, a number of sealed-off Philips tubes from Germany to fill the gap before tubes can be produced in Britain. Panels to deal with crystal structure models and miscellaneous equipment have also been set up.

A. M. B. Dovglas

J. N. KELlar

\section{PRODUCTION OF ANTIBIOTICS BY FUSARIA
By A. H. COOK, S. F. COX, T. H. FARMER AND \\ M. S. LACEY \\ Imperial College of Science and Technology, London}

4 ARLIER communications ${ }^{1,2,3}$ described the production of an antibiotic pigment, javanicin, by Fusarium javanicum, and other Fusaria were also observed ${ }^{1}$ to give rise to antibiotic metabolism solutions. So far, the examination of twenty-two Fusarium strains has revealed a frequent property of this kind; for convenience the moulds may be divided into groups according to the kind of activity exhibited by the crude culture fluids.

Group I, equally active against Mycobacterium phlei and Staphylococcus aureus: $F$. javanicum, $F, 6, F \cdot 64$ ( $F$ numbers refer to strains which areus : javanicum,

Group II, more active against Myco, phlei than against Staph. aureus : $F$. lateritium, $F$. avenaceum, $F$. sambucinum, $F$. dianthii, $F$. fructigenum, $F .63, F .75$ (probably a further strain of $F$. lateritium),
. lianthit, . fructigenum, $F .63, F .75$ (probably a further strain of $F$. lateritium). Group III, active against Myco. phlei, inactiv

aureus: $F$. culmorum (Str. 61), F.72, F.91, F.101.
Group IV, inactive against both Myco. phlei and Staph, aureus: $F$. oxysporum cubense, $F$. culmorum (2nd strain), $F$. coruleum, $F .8$, F. oxysporum cubense,

Clearly this classification may depend on the cultural conditions employed, and it would in any event be less significant if the varying activities were merely due to varying proportions of two antibiotics or classes of antibiotics. Closer examination, however, has afforded chemical evidence which suggests that this division may reflect a more fundamental biochemical grouping.

The antibiotics produced by $F$. lateritium, $F$. avenaceum, $F$. fructigenum, $F$. sambucinum and $F .75$ (probably also a strain of $F$. lateritium) (Group II above) under selected conditions have now all been isolated in pure crystalline state. Excepting the 